\title{
BASES PARA A PADRONIZAÇÃO DO TESTE DE GERMINAÇÃO EM TRÊS ESPÉCIES DE Solanum $\mathrm{L}^{1}{ }^{1}$
}

\author{
*ESTELA DALPIM CASTELLANI², IVOR BERGEMANN DE AGUIAR ${ }^{3}$, RINALDO CÉSAR DE PAULA ${ }^{3}$
}

\begin{abstract}
RESUMO - Foi objetivo deste trabalho obter informações básicas sobre a germinação de sementes de três espécies do gênero Solanum: S. granuloso-leprosum (gravitinga), S. lycocarpum (lobeira) e S. pseudoquina (quina-de-são paulo). Dependendo da espécie, foram testados diferentes lotes, bem como sementes de diferentes densidades e colorações. Os testes de germinação foram conduzidos a $25^{\circ} \mathrm{C}$ e a $20-30^{\circ} \mathrm{C}$, com fotoperíodo de oito horas sob luz branca, sobre papel de filtro. Foram avaliados a porcentagem final e o índice de velocidade de germinação das sementes e determinados os períodos de duração do teste, adotando diferentes critérios de germinação. Os resultados mostraram que as sementes de gravitinga de baixa densidade devem ser descartadas; as sementes de gravitinga de coloração amarela e as de quina-de-são paulo de coloração verde são de maior qualidade fisiológica; houve diferença na germinação das sementes de lobeira e de quina-de-são paulo extraídas de diferentes lotes. A alternância da temperatura e luz beneficiou a germinação das sementes das três espécies. O teste padrão de germinação, teve a duração de 60 dias para as sementes de gravitinga (primeira contagem com 37 dias), de 62 dias para as de quina-de-são paulo (primeira contagem com 33 dias) e de 88 dias para as de lobeira (primeira contagem com 39 dias). Quando o critério botânico para germinação foi adotado (emissão da raiz primária) houve redução no período de duração de germinação em 30 dias para as sementes de gravitinga e de quina-de-são paulo e de 58 dias para as sementes de lobeira.
\end{abstract}

Termos para indexação: sementes florestais, qualidade fisiológica, temperatura, densidade, coloração.

\section{BASIS FOR STANDARDIZATION OF THE GERMINATION TEST IN THREE Solanum L. SPECIES}

\begin{abstract}
This study aimed to obtain basic information about the seed germination of three species of the Solanum genus (Solanaceae), recommended for restoration of degraded lands: $S$. granuloso-leprosum, S. lycocarpum and S. pseudoquina. Depending on the species, different seedlots were tested as well as seeds of different densities and colours. The germination tests were performed at constant $\left(25^{\circ} \mathrm{C}\right)$ and alternating temperatures $\left(20-30^{\circ} \mathrm{C}\right)$, under eight hours photoperiod and with filter paper as substrate. Both total germination percentage and germination speed index were evaluated and the duration of the tests was determined, considering different criteria for germination. The results showed that seeds of $S$. granuloso-leprosum with low density should be discarded; yellow seeds of S. granuolo-leprosum and green seeds of S. pseudoquina showed higher physiological quality; difference in seed germination between seedlots of $S$. lycocarpum and S. pseudoquina was observed.
\end{abstract}

${ }^{1}$ Submetido em 16/03/2008. Aceito para publicação em 08/09/2008. Parte da Tese de Doutorado do primeiro autor apresentada a UNESP/FCAV

${ }^{2}$ Bióloga, Coordenadora do Núcleo Temático Água e Florestas do Fundo Nacional do Meio Ambiente, Ministério do Meio Ambiente, AOS-4, Bloco
B, Ap. 402, CEP 70.660-042, Brasília-DF, e-mail: estela.castellani@gmail. com;

${ }^{3}$ Docente do Depto. de Produção Vegetal da UNESP/FCAV, CEP 14884900, Jaboticabal-SP, e-mail: ivor@netsite.com.br e repaula@fcav.unesp.br 


\begin{abstract}
Alternating temperature was beneficial for seed germination of the three studied species. The standard germination test (normal seedlings), lasted for 60 days for S. granuloso-leprosum (first count at 37 days), 62 days for $S$. pseudoquina (first count at 33 days) and 88 days for $S$. lycocarpum (first count at 39 days). When the botanical criteria for seed germination (primary root emission) was used there was a decrease in the period of time for germination of 30 days for seeds of $S$. granuloso-leprosum and S. pseudoquina and in 58 days for seeds of S. lycocarpum.
\end{abstract}

Index terms: forest seeds, physiological quality, temperature, density, colour.

\section{INTRODUÇÃO}

A necessidade de estabelecer padrões de germinação a serem usados em laboratórios de análise de sementes, para espécies florestais nativas do Brasil, vem sendo ressaltada por autores como Figliolia e Piña-Rodrigues (1995), Perez (1995) e Souza-Silva et al. (2001). A maioria das espécies carece de informações científicas sobre as condições para a germinação das sementes, que constituem a base para a avaliação da sua qualidade. Essa é uma realidade para as espécies do gênero Solanum, cujas informações, quando disponíveis, são insuficientes ou apenas de ordem prática.

A temperatura é um fator determinante para a germinação das sementes, atuando na velocidade de absorção de água, bem como nas reações bioquímicas que desencadeiam todo o processo germinativo (Carvalho e Nakagawa, 2000). Sementes de algumas espécies germinam melhor no regime de temperatura constante, enquanto que as de outras requerem temperatura alternada para promover boa germinação. Segundo Borges e Rena (1993), essa exigência de alternância da temperatura corresponde a uma adaptação às flutuações naturais do ambiente.

Três espécies do gênero Solanum são indicadas na Resolução número 08 da Secretaria do Meio Ambiente, de 07 de março de 2007, para recompor áreas ciliares degradadas no Estado de São Paulo (SMA, 2007): S. granuloso-leprosum, S. lycocarpum e S. pseudoquina.

S. granusolo-leprosum Dunal ocorre nas regiões sudeste e sul do Brasil, sendo conhecida, principalmente, por gravitinga (Roe, 1972). Slycocarpum A. St. Hil., denominada principalmente de lobeira ou fruta-do-lobo, ocorre naturalmente nas regiões tropicais e subtropicais brasileiras, especialmente nos cerradões, cerrados e campos cerrados (Almeida et al., 1998; Lorenzi, 1998). S. pseudoquina A. St. Hil., conhecida popularmente como quina-de-são paulo, é típica da mata latifoliada semidecidual de altitude, ocorrendo nos estados de Minas Gerais, São Paulo e Paraná (Lorenzi, 1998).

Recentemente, Castellani et al. (2007) relataram aspectos referentes à coleta de frutos, extração e beneficiamento das sementes dessas três espécies. Os autores salientaram as diferenças entre lotes, densidade e coloração das sementes. Em vista do exposto, este trabalho teve como objetivo obter informações básicas sobre a germinação das sementes dessas três espécies, visando subsidiar a padronização do teste de germinação em atividades de análise de sementes e de estudos de fisiologia de sementes.

\section{MATERIAL E MÉTODOS}

Este trabalho foi realizado na UNESP (Universidade Estadual Paulista), Campus de Jaboticabal, SP, no Laboratório de Sementes de Plantas Hortícolas e Florestais do Departamento de Produção Vegetal. Para a coleta dos frutos, bem como a extração e o beneficiamento das sementes, foram adotados os procedimentos descritos por Castellani et al. (2007).

Os frutos de $S$. granuloso-leprosum (gravitinga) foram coletados no Campus da UNESP de Jaboticabal em agosto de 2000. Após a extração, as sementes foram separadas pela densidade em dois sublotes (maior e menor densidade, correspondendo a sementes que decantaram e flutuaram no teste de imersão em água, respectivamente) e, dentro de cada sublote, separadas pela coloração em amarelas e escuras. O teste de germinação teve a duração de 78 dias.

Para S. lycocarpum (lobeira) foram utilizadas sementes extraídas de três lotes de frutos, um coletado em Nepomuceno (MG) em fevereiro de 2000 e os outros dois em Jaboticabal (SP) em março e maio de 2000. As sementes permaneceram armazenadas em câmara fria até a instalação do teste de germinação, em junho de 2000. O teste teve a duração de 95 dias.

Para S. pseudoquina (quina-de-são paulo) foram usados três lotes procedentes de Caconde (SP). Um lote foi coletado em abril e os outros dois em maio de 2000. As sementes de um dos lotes coletados em maio foram separadas pela coloração em três sublotes, correspondendo a sementes escuras, amarelas e verdes. Os testes de germinação foram 
instalados em junho de 2000 e encerrados após 67 dias.

Antes da instalação do teste de germinação, foi determinado o teor de água das sementes pelo método de estufa a $105 \pm 3^{\circ} \mathrm{C}$ (Brasil, 1992). Foram utilizadas três repetições de 50 sementes para a lobeira e de aproximadamente $0,07 \mathrm{~g}$ para a gravitinga e $0,27 \mathrm{~g}$ para a quina-de-são paulo.

Os testes de germinação foram conduzidos em germinadores de câmara (BOD), com fotoperíodo de oito horas, sob luz branca fornecida por lâmpadas fluorescentes, com temperatura constante de $25^{\circ} \mathrm{C}$ e alternada de $20-30^{\circ} \mathrm{C}$. As sementes foram colocadas sobre o substrato (duas folhas de papel de filtro), dentro de caixas de plástico transparente com tampa, de $11 \times 11$ x $3 \mathrm{~cm}$. Esse substrato é recomendado para sementes achatadas (Figliolia et al., 1993), como é o caso das sementes das espécies estudadas (Castellani et al., 2008).

Foram adotados três critérios para considerar a semente germinada: o botânico (emissão da raiz primária, segundo Labouriau, 1983); a emissão dos cotilédones; e o critério tecnológico (plântulas normais, segundo Labouriau, 1983 e Brasil, 1992). As contagens das sementes germinadas foram efetuadas a cada dois dias, a partir do início da germinação. Os resultados foram avaliados em termos de capacidade (porcentagem final de sementes germinadas) e índice de velocidade de germinação (Maguire, 1962).

No caso do critério botânico, foram consideradas germinadas as sementes que emitiram raizes primárias com pelo menos $1,0 \mathrm{~mm}$ de comprimento para a gravitinga, $3,0 \mathrm{~mm}$ para a lobeira e $1,5 \mathrm{~mm}$ para a quina-de-são paulo, e geotropismo positivo.

A diferença entre as amostras destinadas à determinação do teor de água das sementes, bem como no tamanho da raiz primária, quando foi adotado o critério botânico, é devida à diferença no peso e no tamanho das sementes de cada espécie, apresentada por Castellani et al. (2007) e Castellani et al. (2008), respectivamente.

Foi adotado o delineamento experimental inteiramente casualizado, com quatro repetições de 25 sementes por tratamento, em esquema fatorial o qual foi variável por espécie. Assim, para gravitinga o esquema fatorial foi 2 x 2 x 2 ( 2 densidades $\times 2$ colorações $\times 2$ condições de temperatura), para lobeira, 3 × 2 (3 lotes $\times 2$ condições de temperatura) e para quina-de-são paulo, 5 x 2 (5 lotes x 2 condições de temperatura). Os dados de porcentagem de germinação foram transformados em arco seno $\sqrt{P / 100}$ (Snedecor e Cochran, 1967). As médias foram comparadas pelo teste de Tukey, a 5\% de probabilidade. Para o melhor tratamento de cada espécie, foram elaboradas as curvas de germinação acumulada e feita a análise de correlação entre os resultados finais obtidos para os diferentes critérios de germinação.

\section{RESULTADOS E DISCUSSÃO}

Para as três espécies e os três critérios de contagem, houve efeito significativo de cada fator testado na porcentagem e na velocidade de germinação das sementes. A interação entre eles também foi significativa. São apresentados apenas os valores de plântulas normais, porque os resultados das análises estatísticas referentes aos outros critérios de germinação (emissão da raiz primária e dos cotilédones) foram semelhantes ao das plântulas normais.

As sementes de $S$. granuloso-leprosum (gravitinga) de menor densidade apresentaram $5,7 \%$ de água no momento da instalação do experimento, flutuaram na água e apresentaram baixa qualidade fisiológica. As sementes de maior densidade apresentavam $8,0 \%$ de água, decantaram na água e apresentaram qualidade fisiológica superior. Independentemente da densidade, as sementes amarelas germinaram em maior porcentagem e mais rapidamente do que às escuras (Tabela 1).

O comportamento germinativo das sementes de menor densidade não foi afetado pelo regime de temperatura apresentando valores muito baixos em ambas as condições, mas as sementes de maior densidade apresentaram desempenho superior na temperatura alternada de $20-30^{\circ} \mathrm{C}$. Da mesma forma, as sementes amarelas apresentaram germinação superior no regime de temperatura alternada, enquanto as escuras germinaram com a mesma velocidade nos dois regimes de temperatura, mas em maior porcentagem na temperatura alternada

Em função desses resultados, as sementes que flutuaram na água, durante a extração, devem ser excluídas do lote. Entre as sementes de maior densidade, as de coloração escura não apresentaram boa capacidade germinativa, mas podem permanecer no lote, pois sua eliminação manual é difícil, devendo ser compensada na semeadura.

A diferença na coloração das sementes pode estar relacionada com o estádio de maturação, uma vez que os frutos das três espécies estudadas não apresentam mudanças de coloração ou outro índice morfológico visual que indique a maturidade fisiológica (Castellani et al., 2007). Em algumas espécies do gênero Qualea, também foram observadas sementes de diferentes colorações. Em $Q$. grandiflora, as sementes marrom-escuras são viáveis e as marrom-claras são inviáveis (Felippe, 1990); em Q. cordata, as sementes escuras não possuem embrião, enquanto que 
as claras são viáveis (Godoy e Felippe, 1992). Sementes de Phyllanthus amarus são de coloração verde-escura (maior capacidade germinativa) e marrom-clara (menor capacidade germinativa), como constataram Unander et al. (1995). Em outras espécies do mesmo gênero ( $P$. niruri e $P$. tenellus), as sementes de coloração marrom apresentaram mais massa e maior porcentagem de germinação do que as de coloração amarela (Venturi e Randi, 1997).

As curvas de germinação acumulada para os três critérios de contagem, referentes ao melhor tratamento, estão apresentadas na Figura 1. Não foram observadas plântulas anormais.

TABELA 1. Porcentagem (\%G) e índice de velocidade (IVG) de germinação (plântulas normais) das sementes de Solanum granuloso-leprosum (gravitinga) de diferentes densidades e colorações, submetidas às temperaturas constantes $\left(25^{\circ} \mathrm{C}\right)$ e alternada $\left(20-30^{\circ} \mathrm{C}\right)$. Lote coletado em Jaboticabal (SP) em agosto de 2000.

\begin{tabular}{|c|c|c|c|c|}
\hline \multirow{2}{*}{$\begin{array}{l}\text { Densidade das } \\
\text { sementes }\end{array}$} & \multicolumn{4}{|c|}{ Coloração das sementes } \\
\hline & Amarela $(\% \mathrm{G}) *$ & Escura $(\% \mathrm{G})$ & Amarela (IVG) & Escura (IVG) \\
\hline Maior & $71 a A$ & $5 b A$ & $0,48 a A$ & $0,04 b A$ \\
\hline Menor & $6 a B$ & $0 b B$ & $0,04 a B$ & $0,00 b B$ \\
\hline \multirow{2}{*}{$\begin{array}{l}\text { Densidade das } \\
\text { sementes }\end{array}$} & \multicolumn{4}{|c|}{ Regime de temperatura } \\
\hline & $25^{\circ} \mathrm{C}(\% \mathrm{G})$ & $20-30^{\circ} \mathrm{C}(\% \mathrm{G})$ & $25^{\circ} \mathrm{C}(\mathrm{IVG})$ & $20-30^{\circ} \mathrm{C}(\mathrm{IVG})$ \\
\hline Maior & $26 b A$ & $50 a A$ & $0,12 b A$ & $0,40 a A$ \\
\hline Menor & $2 a B$ & $4 a B$ & $0,01 a B$ & $0,03 a B$ \\
\hline \multirow{2}{*}{$\begin{array}{l}\text { Coloração das } \\
\text { sementes }\end{array}$} & \multicolumn{4}{|c|}{ Regime de temperatura } \\
\hline & $25^{\circ} \mathrm{C}(\% \mathrm{G})$ & $20-30^{\circ} \mathrm{C}(\% \mathrm{G})$ & $25^{\circ} \mathrm{C}(\mathrm{IVG})$ & $20-30^{\circ} \mathrm{C}(\mathrm{IVG})$ \\
\hline Amarela & $27 b A$ & $49 a A$ & $0,13 b A$ & $0,40 a A$ \\
\hline Escura & $1 b B$ & $5 a B$ & $0,00 a B$ & $0,04 a B$ \\
\hline
\end{tabular}

Coeficiente de variação: $28,21 \%$ para $\% \mathrm{G}$ e $27,51 \%$ para IVG

* Para cada parâmetro avaliado, médias seguidas da mesma letra, minúscula nas linhas e maiúscula nas colunas, não diferem entre si (P>0,05).

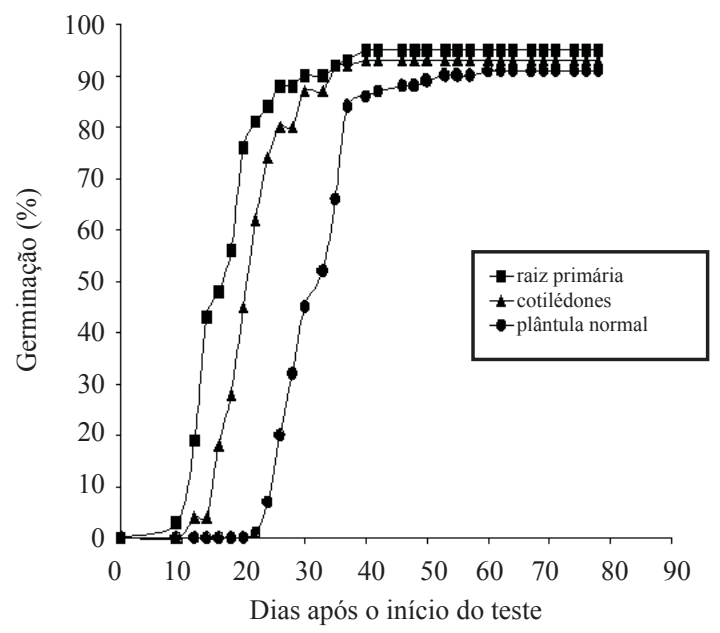

FIGURA 1. Curvas de germinação acumulada das sementes de Solanum granuloso-leprosum (gravitinga) de coloração amarela que decantaram em água e foram incubadas a $20-30^{\circ} \mathrm{C}$, que emitiram raiz primária (critério botânico), das que emitiram cotilédones e das que produziram plântulas normais (critério tecnológico). Lote coletado em Jaboticabal (SP) em agosto de 2000. 
O coeficiente de correlação entre os critérios de contagem variou de 0,995 a 0,998, indicando alta correspondência entre os mesmos. A curva referente ao critério tecnológico estabilizou-se aos 60 dias, com 90\% de plântulas normais. Esse valor foi obtido com 30 dias, pelo critério botânico, e a curva estabilizou-se aos 40 dias, com $95 \%$ de germinação. Nota-se, pelo critério tecnológico, que houve alta porcentagem de germinação aos 37 dias, obtendose $84 \%$ de plântulas normais; essa pode ser a data da primeira contagem. Considerando a emissão dos cotilédones, a curva estabilizou-se aos 40 dias, com $93 \%$ de germinação.

As sementes dos três lotes de S. lycocarpum (lobeira) apresentaram $6,9 \%$ de água no momento da instalação do experimento. Para os três lotes, a porcentagem e a velocidade de germinação foram maiores na temperatura alternada e o lote 2 foi o de qualidade superior, nos dois regimes de temperatura (Tabela 2). A $25^{\circ} \mathrm{C}$, não houve diferença entre os lotes 1 e 3 , mas a $20-30^{\circ} \mathrm{C}$ o lote 3 foi superior ao lote 1 .

TABELA 2. Porcentagem (\%G) e índice de velocidade (IVG) de germinação (plântulas normais) das sementes de Solanum lycocarpum (lobeira) de diferentes lotes, submetidas às temperaturas constantes $\left(25^{\circ} \mathrm{C}\right) \mathrm{e}$ alternada $\left(20-30^{\circ} \mathrm{C}\right)$. Lote 1 coletado em Nepomuceno (MG) em fevereiro de 2000; lotes 2 e 3 coletados em Jaboticabal (SP) em março e maio de 2000, respectivamente.

\begin{tabular}{|c|c|c|c|c|}
\hline \multirow{2}{*}{ Procedência (lote) } & \multicolumn{2}{|c|}{$\% \mathrm{G}^{*}$} & \multicolumn{2}{|c|}{ IVG } \\
\hline & $25^{\circ} \mathrm{C}$ & $20-30^{\circ} \mathrm{C}$ & $25^{\circ} \mathrm{C}$ & $20-30^{\circ} \mathrm{C}$ \\
\hline Lote 1 & $5 \mathrm{bB}$ & $31 \mathrm{aC}$ & $0,03 \mathrm{bB}$ & $0,16 \mathrm{aC}$ \\
\hline Lote 2 & $26 \mathrm{bA}$ & $94 \mathrm{aA}$ & $0,15 \mathrm{bA}$ & $0,51 \mathrm{aA}$ \\
\hline Lote 3 & $5 \mathrm{bB}$ & $56 \mathrm{aB}$ & $0,03 \mathrm{bB}$ & $0,32 \mathrm{aB}$ \\
\hline
\end{tabular}

* Para cada parâmetro avaliado, médias seguidas da mesma letra, minúscula nas linhas e maiúscula nas colunas, não diferem entre si (P>0,05).

A diferença entre lotes pode estar ligada a vários fatores, dentre eles o estádio de maturação das sementes, como comentado para a espécie anterior. Para as três espécies estudadas, não ocorrem modificações visuais indicando a maturação dos frutos, que foram mantidos por cerca de uma semana em saco de polietileno, a meia sombra, para facilitar o amolecimento da polpa; os frutos que não amoleceram foram descartados (Castellani et al., 2007). Os autores relataram que na mesma árvore são encontrados frutos em diferentes estádios de desenvolvimento, o que pode ter contribuído para a diferença entre os lotes.

$\mathrm{Na}$ temperatura de $25^{\circ} \mathrm{C}$, muitas sementes permaneceram intumescidas, mas não germinaram, enquanto que a 20$30^{\circ} \mathrm{C}$, a quantidade de sementes nessa condição foi baixa, para os três lotes. Isso pode ser resultado da necessidade de alternância da temperatura para que o processo germinativo seja devidamente desencadeado.

Algumas sementes, após o contato com o substrato úmido, liberaram através da micrópila uma substância branca que pode ser confundida com a raiz primária. $\mathrm{O}$ fato de ter-se considerado germinadas as sementes com raiz primária de pelo menos 3,0mm de comprimento e geotropismo positivo contribuiu para a adequada avaliação da germinação. Após a emissão da raiz primária, algumas plântulas não emitiram cotilédones, mas houve o surgimento das primeiras folhas; mesmo nessa situação, elas tiveram bom desenvolvimento e foram consideradas normais.

A ocorrência de plântulas anormais foi pequena, as quais geralmente não apresentaram raiz primária, de modo a haver primeiramente a emissão do hipocótilo. Outra anormalidade constatada foi a emissão inicial dos cotilédones através da lateral oposta à micrópila.

A Figura 2 ilustra as curvas de germinação acumulada das sementes do melhor tratamento, para os três critérios de contagem adotados. O coeficiente de correlação para os resultados finais variou de 0,991 a 0,997 , revelando semelhança na germinação avaliada pelos três critérios.

Pelo critério botânico, a curva ficou estabilizada aos 50 dias com $95 \%$ de germinação, mas aos 30 dias $92,5 \%$ das sementes já haviam emitido a raiz primária. Considerando a emissão dos cotilédones e a produção de plântulas normais, as curvas foram semelhantes. Aos 30 dias, apenas $28 \%$ das sementes haviam produzido plântulas normais e aos 50 dias $72 \%$ das sementes haviam emitido os cotilédones ou gerado plântulas normais. Pelo critério tecnológico, nota-se um pico aos 33 dias com $48 \%$ de plântulas normais, que pode ser considerada a primeira contagem de germinação. Outro pico foi constatado aos 65 dias, com $88 \%$ de plântulas normais, mas a quantidade máxima (94\%) foi obtida após 88 dias da instalação do teste de germinação. 


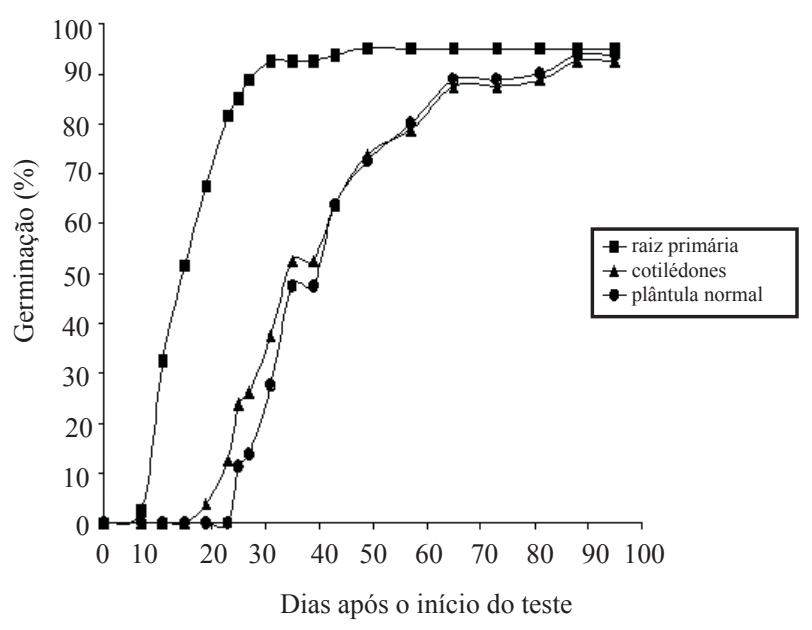

FIGURA 2. Curvas de germinação acumulada das sementes de Solanum lycocarpum (lobeira) incubadas a $20-30^{\circ} \mathrm{C}$, que emitiram raiz primária (critério botânico), das que emitiram cotilédones e das que produziram plântulas normais (critério tecnológico). Lote 2 coletado em Jaboticabal (SP) em março de 2000.

O teor de água e a qualidade fisiológica dos lotes de sementes de $S$. pseudoquina (quina-de-são paulo) podem ser observados na Tabela 3. O lote 2 revelou-se de baixa qualidade, principalmente para as sementes escuras e amarelas. A qualidade das sementes verdes foi um pouco melhor, porém, inferior a dos lotes 1 e 3, que também apresentaram sementes de coloração verde. Esse resultado sugere que na maturidade fisiológica, as sementes de quinade-são paulo adquirem a coloração verde e o teor de água se equilibra em torno de $7,0 \%$.

Considerando os dois melhores lotes, verifica-se que o lote 1 não foi afetado pelo regime de temperatura, enquanto que o lote 3 germinou em maior porcentagem e mais rapidamente na temperatura alternada. Comparando os dois regimes de temperatura, verifica-se que a $25^{\circ} \mathrm{C}$ não houve diferença entre os dois lotes, quanto à capacidade germinativa, mas a $20-30^{\circ} \mathrm{C}$ o lote 3 foi superior ao lote 1 . Quanto à velocidade de germinação o comportamento foi oposto: na temperatura alternada não houve diferença entre os dois lotes, mas na temperatura constante as sementes do lote 1 germinaram mais rapidamente do que as do lote 3 .

$\mathrm{Na}$ temperatura de $20-30^{\circ} \mathrm{C}$ foi constatada menor quantidade de sementes intumescidas, que não germinaram até o final do teste, comparativamente à temperatura constante. Isso reforça o requerimento da alternância da temperatura para favorecer o processo germinativo. As diferenças entre lotes e entre coloração das sementes já foram discutidas anteriormente, com base em Castellani et al. (2007).

TABELA 3. Teor de água (TA), porcentagem (\%G) e índice de velocidade (IVG) de germinação (plântulas normais) das sementes de Solanum pseudoquina (quina-de-são paulo) de diferentes lotes e colorações, submetidas ás temperaturas constante $\left(25^{\circ} \mathrm{C}\right)$ e alternada $\left(20-30^{\circ} \mathrm{C}\right)$. Lotes coletados em Caconde (SP): lote $1 \mathrm{em}$ abril e lotes 2 e 3 em maio de 2000.

\begin{tabular}{lccccrc}
\hline Lote & $* \mathrm{TA}$ & \multicolumn{3}{c}{$\% \mathrm{G}$} & & \multicolumn{2}{c}{ IVG } \\
\cline { 3 - 4 } \cline { 6 - 7 } (coloração) & $(\%)$ & $25^{\circ} \mathrm{C}$ & $20-30^{\circ} \mathrm{C}$ & & $25^{\circ} \mathrm{C}$ & $20-30^{\circ} \mathrm{C}$ \\
\hline Lote 1 (verde) & 6,9 & $83 \mathrm{aA}$ & $85 \mathrm{aB}$ & & $0,52 \mathrm{aA}$ & $0,50 \mathrm{aA}$ \\
Lote 2 (escura) & 5,4 & $1 \mathrm{bC}$ & $6 \mathrm{aD}$ & & $0,01 \mathrm{aD}$ & $0,04 \mathrm{aC}$ \\
Lote2 (amarela) & 5,7 & $0 \mathrm{aC}$ & $0 \mathrm{aE}$ & & $0,00 \mathrm{aD}$ & $0,00 \mathrm{aC}$ \\
Lote 2 (verde) & 6,3 & $25 \mathrm{aB}$ & $26 \mathrm{aC}$ & & $0,15 \mathrm{aC}$ & $0,14 \mathrm{aB}$ \\
Lote 3 (verde) & 7,1 & $79 \mathrm{ba}$ & $99 \mathrm{aA}$ & & $0,42 \mathrm{bB}$ & $0,57 \mathrm{aA}$ \\
\hline Coeficiente de variação: & \multicolumn{3}{c}{$10,55 \%$} & & \multicolumn{2}{c}{$14,19 \%$} \\
\hline
\end{tabular}

Para cada parâmetro avaliado, médias seguidas da mesma letra, minúscula nas linhas e maiúscula nas colunas, não diferem entre si (P>0,05).

As curvas de germinação acumulada para os três critérios de contagem, referentes ao melhor tratamento, estão ilustradas na Figura 3. Não foram constatadas plântulas anormais. 


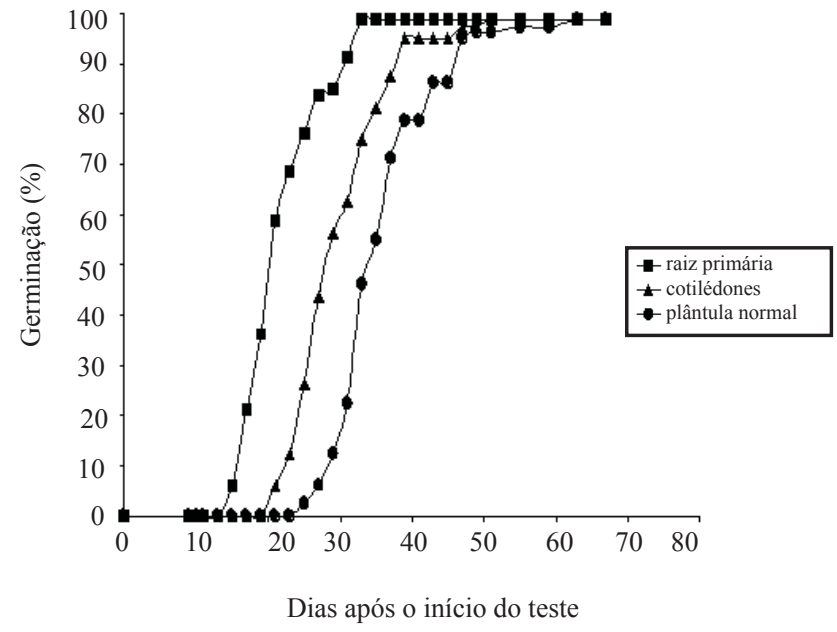

FIGURA 3. Curvas de germinação acumulada das sementes de Solanum pseudoquina (quinade-são paulo) de coloração verde incubadas a 20-30 ${ }^{\circ} \mathrm{C}$, que emitiram raiz primária (critério botânico), das que emitiram cotilédones e das que produziram plântulas normais (critério tecnológico). Lote 3 coletado em Caconde (SP) em maio de 2000.

O coeficiente de correlação entre os dados obtidos pelos três critérios também foi elevado, variando de 0,995 a 0,999 e evidenciando concordância de resultados. A curva referente ao critério tecnológico foi estabilizada aos 62 dias, com $99 \%$ de plântulas normais. Essa mesma porcentagem foi constatada aos 32 dias, quando foi considerado o critério botânico. Foi observado um pico após 39 dias da instalação do teste de germinação, com a produção de $79 \%$ de plântulas normais; essa pode ser a data da primeira contagem. Outro pico foi constatado aos 48 dias, com $95 \%$ de plântulas normais; um pico com essa mesma porcentagem foi constatado para a emissão dos cotilédones, após 39 dias da instalação do teste.

Para as três espécies estudadas, o regime de temperatura alternada beneficiou o processo germinativo, devendo ser recomendado para a condução do teste padrão de germinação. Resultado semelhante foi constatado para sementes de $S$. sessiliflorum (cubiu), uma solanácea arbustiva originária da Amazônia Ocidental (Lopes e Pereira, 2005). Segundo Vázques-Yanes e Orozco-Segovia (1984), as sementes adaptadas a responder às flutuações da temperatura possuem mecanismos enzimáticos que funcionam em diferentes temperaturas; dessa forma, apenas quando ocorrem várias temperaturas ao longo do processo catalisado por essas enzimas, é possível o pleno desencadeamento da germinação.

As Regras para Análise de Sementes (Brasil, 1992) prescrevem que o resultado do teste de germinação seja expresso em porcentagem do número de plântulas normais obtida no final do período de duração do teste. Esse critério foi denominado de tecnológico por Labouriau (1983) e recomendado para os laboratórios de análise de sementes por Figliolia et al. (1993), Figliolia e Piña-Rodrigues (1995) e Figliolia et al. (2007). Entretanto, em alguns trabalhos de pesquisa tem sido utilizado o critério botânico, caracterizado também por Labouriau (1983) pela emissão da raiz primária.

Pelo critério tecnológico, o período de duração do teste de germinação para os melhores lotes das três espécies estudadas neste trabalho foi de 60 dias para a gravitinga, de 88 dias para a lobeira e de 62 dias para a quina-de-são paulo. Pelo critério botânico, o período de duração do teste foi reduzido para 30,32 e 30 dias, respectivamente, conduzindo a um valor semelhante ao obtido para plântulas normais.

Assim, o critério botânico poderá ser utilizado em trabalhos de pesquisa, permitindo considerável economia de tempo para a obtenção dos resultados. Mesmo as Regras para Análise de Sementes recomendam a aplicação de testes rápidos, como o de tetrazólio, para determinar a viabilidade das sementes que germinam lentamente em testes normais. Considerando o longo período de duração do teste de germinação, é justificável a padronização do teste de tetrazólio para as sementes das espécies estudadas. Aplicado antes do teste de germinação, os lotes de baixa qualidade poderão ser descartados, evitando trabalho, bem como o uso de equipamentos, material de consumo e energia.

\section{CONCLUSÕES}

As sementes de $S$. granuloso-leprosum (gravitinga) que flutuam na água devem ser descartadas por apresentarem baixa qualidade fisiológica. As sementes de gravitinga de coloração amarela e as de $S$. pseudoquina (quina-desão paulo) de coloração verde são de melhor qualidade fisiológica. Há diferença no comportamento germinativo das sementes de quina-de-são paulo e de $S$. lycocarpum (lobeira) provenientes de diferentes lotes.

A temperatura alternada de $20-30^{\circ} \mathrm{C}$ beneficia a germinação das sementes das três espécies estudadas.

$O$ teste de germinação, considerando o critério tecnológico, tem a duração de 60 dias para as sementes de 
gravitinga (primeira contagem com 37 dias), de 62 dias para as de quina-de-são paulo (primeira contagem com 33 dias) e de 88 dias para as de lobeira (primeira contagem com 39 dias).

Para fins de pesquisa, poderá ser utilizado o critério botânico de germinação, reduzindo o período de duração do teste em 30 dias para as sementes de gravitinga e de lobeira e em 32 dias para as de quina-de-são paulo.

\section{AGRADECIMENTOS}

À FAPESP, pela concessão de Bolsa de Doutorado para o primeiro autor e ao $\mathrm{CNPq}$ pela concessão de Bolsa de Produtividade em Pesquisa para os outros dois autores.

\section{REFERÊNCIAS}

ALMEIDA, S.P.; PROENÇA, C.E.B.; SANO, S.M.; RIBEIRO, J.F. Cerrado: espécies vegetais úteis. Planaltina: EMBRAPA-CPAC, 1998. 464p.

BORGES, E.E.L.; RENA, A.B. Germinação de sementes. In: AGUIAR, I.B.; PIÑA-RODRIGUES, F.C.M.; FIGLIOLIA, M.B. (Coord.). Sementes florestais tropicais. Brasília, DF: ABRATES, 1993. p.83-135.

BRASIL. Ministério da Agricultura e da Reforma Agrária. Regras para análise de sementes. Brasília, DF: SNDA/ DNDV/CLAV, 1992. 365p.

CARVALHO, N.M.; NAKAGAWA, J. Germinação de sementes. In: CARVALHO, N.M.; NAKAGAWA, J. (Ed.) Sementes: ciência, tecnologia e produção. Jaboticabal: FUNEP, 2000. p.128-166.

CASTELlANI, E.D., AGUIAR, I.B., PAULA, R.C. Colheita de frutos, extração e beneficiamento de sementes de solanáceas arbóreas. Informativo ABRATES, Pelotas, v.17, n.1-3, p. 69-75, 2007.

CASTELlANI, E.D.; DAMIÃO FILHO, C.F.; AGUIAR, I.B.; PAULA, R.C. Morfologia de frutos e sementes de espécies arbóreas do gênero Solanum L. Revista Brasileira de Sementes, v.30, n.1, p.102-113, 2008.

FELIPPE, G.M. Qualea grandiflora: the seed and its germination. Revista Brasileira de Botânica, v.13, n.1, p.33-37, 1990.

FIGLIOLIA, M.B.; OLIVEIRA, E.C.; PINÃ-RODRIGUES, F.C.M. Análise de sementes. In: AGUIAR I.B.; PIN ÃRODRIGUES, F.C.M.; FIGLIOLIA, M.B. (Coord.). Sementes florestais tropicais. Brasília,DF: ABRATES, 1993. p.137-174.
FIGLIOLIA, M.B.; PIÑA-RODRIGUES, F.C.M. Considerações práticas sobre o teste de germinação. In: SILVA, A.; PIÑA-RODRIGUES, F.C.M.; FIGLIOLIA, M.B. Manual técnico de sementes florestais. São Paulo: Instituto Florestal, 1995. p.45-59. (IF Série Registros, 14).

FIGLIOLIA, M.B.; PIÑA-RODRIGUES, F.C.M; NOGUEIRA, E.S. Controle de qualidade de sementes florestais: propostas de parâmetros técnicos. In: PIÑARODRIGUES, F.C.M.; FREIRE, J.M.; LELES, P.S.S.; BREIER, T.B. Parâmetros técnicos para a produção de sementes florestais. Seropédica: UFRRJ, 2007. p. 143-187.

GODOY, S.M.A.; FELIPPE, G.M. Qualea cordata: a semente e sua germinação. Revista Brasileira de Botânica, v.15, n.1, p.17-21, 1992.

LABOURIAU, L.G. Capacidade e velocidade de germinação. In: LABOURIAU, L.G. A germinação das sementes. Washington: OEA, 1983. p.45-62.

LOPES, J.C.; PEREIRA, M.D. Germinação de sementes de cubiu em diferentes substratos e temperaturas. Revista Brasileira de Sementes, v.27, n.2, p.146-150, 2005.

LORENZI, H. Árvores brasileiras: manual de identificação e cultivo de plantas arbóreas nativas do Brasil. 2.ed. Nova Odessa: Editora Plantarum, 1998. v.2, 352p.

MAGUIRE, J.D. Speed of germination-aid selection and evaluation for seedling emergence and vigor. Crop Science, v.2, n.2, p.176-177, 1962.

PEREZ, S.C.J.G.A. Ecofisiologia de sementes florestais. Informativo ABRATES, Curitiba, v.5, n.3, p.13-30, 1995.

ROE, K.E. A revision of Solanum section Brevantherum (Solanaceae). Brittonia, Bronx, v.24, n.3, p.239-278, 1972.

SÃO PAULO. Secretaria do Meio Ambiente do Estado de São Paulo. Resolução SMA 08. - Altera a Resolução SMA 21, de 21/11/2001 e Resolução SMA 47, de 27/11/2003. Fixa orientação para o reflorestamento heterogêneo de áreas degradadas e dá providências correlatas. São Paulo, 07 de março de 2007. Disponível em: <http://www.ibot.sp.gov.br/ legislacao/legislacao.htm.>. Acesso em: 04 jan. 2008.

SNEDECOR, G.W.; COCHRAN, W.G. Statistical methods. 6.ed. Ames: Iowa State College Press, 1967. 593p.

SOUSA-SILVA, J.C.; RIBEIRO, J.F.; FONSECA, C.E.L.; ANTUNES, N.B. Germinação de sementes e emergência de plântulas de espécies arbóreas e arbustivas que ocorrem em Mata de Galeria. In: RIBEIRO, J.F.; FONSECA, C.E.L.; SOUSA-SILVA, J.C. Cerrado: caracterização e recuperação de mata de galeria. Planaltina: Embrapa Cerrados, 2001. p.379-422. 
UNANDER， D.W.U.; BRYAN， H.H.; LANCE， C.J.; McMILLAN JR, R.T. Factors affecting germination and stand establishment of Phyllanthus amarus (Euphorbiaceae). Economic Botany, v.49, n.1, p.49-55, 1995.

VÁZQUEZ-YANES, C.; OROZCO-SEGOVIA, A. Fisiología ecológica de las semillas de árboles de la selva tropical: un reflejo de su ambiente. Ciencia, n.35, p.191201, 1984.

VENTURI, S.; RANDI, A.M. Influência da coloração das sementes na germinação de Phyllanthus tenellus Roxb. e Phyllanthus niruri L. (Euphorbiaceae). Acta Botanica Brasilica, v.11, n.1, p.87-94, 1997. 